\title{
Effect of feeding frequency of a diet containing soya hulls on the food intake and behaviour of dogs*
}

\author{
Tabyta T. Sabchuk, Juliana R. Silva, Francielle O. Marx, Ananda P. Felix ${ }^{\dagger}$, Alex Maiorka and \\ Simone G. Oliveira \\ Universidade Federal do Paraná, Rua dos Funcionários, 1540, 80035-050, Curitiba, PR, Brazil
}

(Received 1 November 2013 - Final revision received 27 February 2014 - Accepted 13 March 2014)

Journal of Nutritional Science (2014), vol. 3, e60, page 1 of 4

doi:10.1017/jns.2014.34

Abstract

Dietary fibre may promote satiety and reduce energy consumption per gram of food. Associated with feeding management, dietary fibre may contribute to reduce anxiety in dogs submitted to food restriction to lose weight. The objective of the present study was to evaluate the food intake and the behaviour of dogs fed diets without soya hulls $(0 \mathrm{SH})$ or with soya hulls $(16 \mathrm{SH})$ once $(1 \times)$ or twice $(2 \times)$ daily. Eight adult Beagle dogs, with $11 \cdot 3$ (sE 1.6$)$ kg body weight (BW), 4.1 (SE 0.1) years of age and body condition score between 4 and 7 , were distributed in $4 \times 4$ Latin square design ( $n 8 /$ treatment, $5 \mathrm{~d} /$ period) in a $2 \times 2$ factorial arrangement $(0 \mathrm{SH} v .16 \mathrm{SH} ; 1 \times v .2 \times)$. Food allowance was $50 \%$ in excess of the daily metabolisable energy (ME) requirements; food residues were weighed. The behavioural test consisted in continuously observations for $24 \mathrm{~h}$, using the scanning sampling technique (observations every 10 min). General behaviours, such as sleeping, barking, standing and others were recorded. Food intake in $\mathrm{g} / \mathrm{kg}$ BW ${ }^{0.75}$ per $\mathrm{d}$ of $0 \mathrm{SH}$ and $16 \mathrm{SH}$ was not different $(P>0 \cdot 05)$. However, dogs fed the 0SH diet presented higher $(P>0 \cdot 05)$ energy intake $\left(\mathrm{kJ} / \mathrm{kg} \mathrm{BW}^{0.75}\right.$ per $\left.\mathrm{d} ; P<0 \cdot 05\right)$ compared with those fed the $16 \mathrm{SH}$ diet. Dogs fed $2 \times$ daily had higher intake, both in $\mathrm{g}$ and in $\mathrm{kJ}$, compared with those fed $1 \times$, independently of diet. There was no interaction between diets and feeding frequency $(P>0 \cdot 05)$. No behavioural differences were observed $(P>0 \cdot 05)$. The diet containing $16 \mathrm{SH}$, despite reducing ME intake, did not restrict food intake (in $\mathrm{g}$ ). Dogs fed $1 \times$ per $\mathrm{d}$ had lower food intake, possibly due to gastric capacity limitation.

Key words: Canine nutrition: Fibre sources: Obesity

Pet obesity has become increasingly common in many countries $^{(1)}$. In the USA, it is estimated that approximately $40 \%$ of the dogs are overweight or obese ${ }^{(2)}$. Therefore, different feeding management strategies have been applied together with different diets to control and/or to reduce body weight (BW). The inclusion of fibre in foods may help, as they dilute dietary energy and may provide the sensation of satiety in the short and long terms ${ }^{(3)}$.

Bosch et al. ${ }^{(4)}$ evaluated the influence of dietary macronutrients on general dog behaviour and reported that diets with high-fibre inclusion may promote satiety, as demonstrated by the increased inactivity and lower level of arousal compared with those fed low- fibre diets. According to Asakawa et al. ${ }^{(5)}$, the sensation of hunger in rats increase anxiety. In dogs, this may contribute to the expression of behavioural problems related with anxiety ${ }^{(3)}$.

Both food allowance and fibre physical-chemical characteristics, including fermentability, solubility and viscosity, may determine satiety in animals ${ }^{(2,3)}$. Several studies indicate that fibre effects on satiety may be mainly attributed to soluble fibres $(\mathrm{SF})^{(6)}$, which are more viscous than the insoluble fibres (IF), reducing the food passage rate and stimulating the production and secretion of hormones related to satiety in the gastrointestinal tract ${ }^{(2)}$. However, the dietary inclusion of SF is limited, as they may increase faecal moisture ${ }^{(7)}$.

Abbreviations: BW, body weight; CF, crude fibre; CP, crude protein; IF, insoluble fibre; ME, metabolisable energy; MER, metabolisable energy requirement; SF, soluble fibre; $\mathrm{SH}$, soya hulls.

${ }^{\dagger}$ Corresponding author: Ananda P. Felix, fax + 55413252 4149, email apfelix@ufpr.br

* This article was published as part of the WALTHAM International Nutritional Sciences Symposium Proceedings 2013 
Soya hulls $(\mathrm{SH})$, the fibre source used in the present study, contain mainly IF (IF-to-SF ratio of between 15.4:1 and $\left.5 \cdot 0: 1^{(8)}\right)$. It is widely available in the market and may reduce costs for the pet food industry. Therefore, the objective of the present study was to evaluate food intake, metabolisable energy (ME) intake and the behaviour of dogs fed diets containing or not $\mathrm{SH}$ once or twice daily.

\section{Materials and methods}

The experiment was approved by the Committee of Ethics on Animal Use of the sector of Agrarian Sciences of the Federal University of Paraná, Curitiba, PR, Brazil, under protocol no. 019/2012.

\section{Animals and facilities}

Eight adult Beagle dogs (four males and four females), with 11.3 (SE 1.6) $\mathrm{kg}$ average BW and $4 \cdot 1$ (SE 0.1) years of age and body condition score between 4 and 7 were studied. All dogs were previously submitted to clinical and physical examinations, vaccinated and de-wormed. Dogs were individually housed in concrete kennels with a solarium ( $5 \mathrm{~m}$ long $\times 2 \mathrm{~m}$ wide).

\section{Diets}

The analysed composition of the $\mathrm{SH}$ included in the diet was: $13.0 \%$ crude protein, $72.0 \%$ total dietary fibre, $65.5 \% \mathrm{IF}$, and $6.5 \% \mathrm{SF}$ at an IF:SF ratio of $9.97: 1$. SH were included in the diet replacing maize. Two diets based on maize and poultry by-product meal were formulated. The diet with no inclusion of soya hulls (OSH) contained $28.0 \%$ crude protein, $93.4 \%$ DM, 14.8 \% diethyl ether extract in acid hydrolysis, $14.4 \%$ total dietary fibre, $0.2 \% \mathrm{SF}, 14.1 \% \mathrm{IF}$; and 17.9 $\mathrm{MJ} / \mathrm{g}$ ME. The diet with $16 \%$ soya hulls $(16 \mathrm{SH})$ contained $29.3 \%$ crude protein, $93.4 \% \mathrm{DM}, 12.8 \%$ diethyl ether extract, $24.9 \%$ total dietary fibre, $6.2 \% \mathrm{SF}, 18.7 \% \mathrm{IF}$ and $15.7 \mathrm{MJ} / \mathrm{g}$ ME. The diets were ground in a mill using $1.0 \mathrm{~mm}$ mesh, and were extruded in a single-screw extruder (E-130; Ferraz). Dietary DM, crude protein and diethyl ether extract contents were analysed according to the Association of the Official Analytical Chemists ${ }^{(9)}$. The contents of total dietary fibre, SF and IF were determined according to the method of Prosky et al. ${ }^{(10)}$. Gross energy was determined in a bomb calorimeter (Parr Instrument Co. model 1261). The ME was determined in vivo in a previous total faecal collection digestibility trial with eight adult Beagle dogs, totalling eight replicates per treatment (unpublished results; Tabyta T. Sabchuk, 2013), according to the Association of American Feed Control Officials ${ }^{(11)}$.

\section{Food intake and behavioural evaluations}

The two diets (0SH or $16 \mathrm{SH})$ were offered by two feeding managements, fed once, at $08.00 \mathrm{~h}$, or twice, at 08.00 and $16.00 \mathrm{~h}$, daily. The allowance of the $\mathrm{OSH}$ diet was $50 \%$ in excess of the National Research Council(1) recommendations of $\mathrm{ME}$ maintenance requirements $(\mathrm{MJ} / \mathrm{d}$ ) of dogs, according to the equation: $0.54 \times \mathrm{BW}^{0.75}(\mathrm{~kg})+50 \%$. This allowance was adopted based on the observed feed residues. The $16 \mathrm{SH}$ diet was fed at the same amount (in $\mathrm{g}$ of $\mathrm{DM}$ ) as the $\mathrm{OSH}$ diet. Food intake (offer-residues) was calculated for each meal. The diets were fed for $5 \mathrm{~d}$. Although this was not a digestibility trial, the period of $5 \mathrm{~d}$ was used because, according to the Association of American Feed Control Officials $^{(11)}$, this is the period required for dog's adaptation to the diets and facilities. Also, fibres promote satiety particularly in the short term due to their filling effect in the gastrointestinal system during food intake $\mathrm{e}^{(2,12) \text {. }}$

Dog behaviour was evaluated always on the 4th day of the experimental period for $24 \mathrm{~h}$ using the scanning sampling technique $^{(13)}$. Behaviours were recorded every $10 \mathrm{~min}$, and are expressed as frequency (\%) of occurrence. The following behaviours were recorded: idle standing (on $4 \mathrm{ft}$ ), idle sitting (leaning on the stretched front legs and flexed hind legs), resting (lying on ventral or latero-lateral position and eyes closed), drinking, eating, alert (standing and attentive to movements), socialising (interaction with dogs of the neighbouring kennels), stereotypies (uninterrupted abnormal behaviour) ${ }^{(14)}$, scratching, walking and self-grooming.

\section{Statistical analysis}

Data were analysed according to a replicated Latin square design (four treatments $\times$ four periods) in a $2 \times 2$ factorial arrangement ( $\mathrm{SH}$ dietary inclusion level and feeding management). Every 2 dogs were fed one of the diets in each period, totalling eight replicates per treatment. The experimental unit was one dog. The sum of the squares of the ANOVA was separated in effects of animal, period, SH inclusion level and feeding management effects, as well as effects of the interaction between $\mathrm{SH}$ inclusion level and feeding management. In the $F$ test, differences with $P<0.05$ were considered significant.

The frequencies $(\%)$ of the observed behaviours were analysed by the test of Kruskal-Wallis, with $P<0.05$ indicating significant difference. All analyses were carried out using SAS statistical package (Statistical Analysis System, version 8.2; SAS Inst. Inc., Cary, NC).

\section{Results}

Food intake was not different between diets $0 \mathrm{SH}$ and $16 \mathrm{SH}$ ( $P>0.05$; Table 1). However, the dogs that consumed the $0 \mathrm{SH}$ diet presented greater $\mathrm{ME}$ intake $(P>0 \cdot 05$; Table 1$) \mathrm{com}$ pared with those fed the $16 \mathrm{SH}$ diet. In addition, intake, both in grams and kJ, was greater in dogs fed twice daily compared with those fed once daily. There was no interaction between dietary SH inclusion and feeding frequency $(P>0 \cdot 05)$. No differences were observed in dog's behaviour (Table 2).

\section{Discussion}

Considering the increasing number of obese dogs, foods to control BW need to be developed. These foods may contain restricted energy levels, which may cause the dogs to feel hungry, increasing their anxiety and leading to undesirable behaviours. Therefore, food formulas for obese dogs should 
Table 1. Food intake in g, food intake per body weight (BW) and metabolisable energy (ME) intake of eight dogs fed diets without soya hulls $(\mathrm{OSH})$ or with soya hulls $(16 \mathrm{SH})$ once $(1 \times)$ or twice $(2 x)$ daily

\begin{tabular}{lcccc}
\hline Factors & Treatments & $\begin{array}{c}\text { Intake } \\
(\mathrm{g})^{*}\end{array}$ & $\begin{array}{c}\text { Intake } \\
\left(\mathrm{BW}^{0.75}\right) \dagger\end{array}$ & $\begin{array}{c}\text { ME } \\
\text { intake } \neq\end{array}$ \\
\hline Diets (D) & OSH & 297.31 & 47.06 & 843.30 \\
& $16 \mathrm{SH}$ & 293.34 & 46.43 & 732.79 \\
Feeding & $1 \times$ & 258.02 & 40.74 & 689.02 \\
$\quad$ frequency (FF) & & & & \\
SEM & $2 \times$ & 332.64 & 52.75 & 887.07 \\
P value & & 12.452 & 1.836 & 31.832 \\
D & & & & \\
FF & & 0.854 & 0.836 & 0.037 \\
D $\times$ FF & & 0.016 & $<0.001$ & $<0.001$ \\
& & 0.182 & 0.195 & 0.285 \\
\hline
\end{tabular}

${ }^{*}$ Food intake in $\mathrm{g}$ ( $\mathrm{g}$ 'as is'/dog per d).

†Food intake per BW ${ }^{0.75}$ (g/kg BW ${ }^{0.75}$ per d).

‡ME intake (kJ ME/kg BW ${ }^{0.75}$ per d).

maintain satiety for long periods and, at the same time, allow for the healthy control of BW.

Hunger is controlled by the presence of food in the gastrointestinal tract and by blood levels of nutrients. It is difficult to identify and to measure hunger, the easiest way to assess hunger is by evaluating satiety ${ }^{(15)}$. However, there is no definite protocol to measure satiety ${ }^{(15)}$ in terms of hunger inhibition and that could be measured by the time interval until the next meal or by the amount of food intake in the next meal ${ }^{(16)}$.

Table 2. Median frequency of behaviours observed in eight dogs fed diets without soya hulls $(0 \mathrm{SH})$ or with soya hulls $(16 \mathrm{SH})$ once $(1 \times)$ or twice $(2 x)$ daily

\begin{tabular}{|c|c|c|c|}
\hline Behaviour & Treatments & Median (\%) & $P$ value \\
\hline \multirow[t]{4}{*}{ Idle lying } & OSH $1 \times$ & 8.62 & 0.523 \\
\hline & $16 \mathrm{SH} 1 \times$ & $6 \cdot 21$ & \\
\hline & $\mathrm{OSH} 2 \times$ & $8 \cdot 62$ & \\
\hline & $16 \mathrm{SH} 2 \times$ & 8.97 & \\
\hline \multirow[t]{4}{*}{ Idle sitting } & OSH $1 \times$ & 6.90 & 0.951 \\
\hline & $16 \mathrm{SH} 1 \times$ & $6 \cdot 21$ & \\
\hline & $\mathrm{OSH} 2 \times$ & 7.90 & \\
\hline & $16 \mathrm{SH} 2 \times$ & 7.59 & \\
\hline \multirow[t]{4}{*}{ Idle standing } & OSH $1 \times$ & $2 \cdot 76$ & 0.342 \\
\hline & $16 \mathrm{SH} 1 \times$ & 4.48 & \\
\hline & OSH $2 \times$ & $5 \cdot 52$ & \\
\hline & $16 \mathrm{SH} 2 \times$ & 3.79 & \\
\hline \multirow[t]{4}{*}{ Sleeping } & $\mathrm{OSH} 1 \times$ & 62.07 & 0.759 \\
\hline & $16 \mathrm{SH} 1 \times$ & 64.83 & \\
\hline & $\mathrm{OSH} 2 \times$ & $58 \cdot 62$ & \\
\hline & $16 \mathrm{SH} 2 \times$ & 62.41 & \\
\hline \multirow[t]{4}{*}{ Self-grooming } & $\mathrm{OSH} 1 \times$ & 3.79 & 0.758 \\
\hline & $16 \mathrm{SH} 1 \times$ & $2 \cdot 41$ & \\
\hline & OSH $2 \times$ & $2 \cdot 88$ & \\
\hline & $16 \mathrm{SH} 2 \times$ & $2 \cdot 76$ & \\
\hline \multirow[t]{4}{*}{ Walking in the pen } & $0 \mathrm{SH} 1 \times$ & 2.41 & 0.573 \\
\hline & $16 \mathrm{SH} 1 \times$ & $2 \cdot 76$ & \\
\hline & $0 \mathrm{SH} 2 \times$ & 1.38 & \\
\hline & $16 \mathrm{SH} 2 \times$ & $2 \cdot 41$ & \\
\hline \multirow[t]{4}{*}{ Other† } & $0 \mathrm{SH} 1 \times$ & $10 \cdot 69$ & 0.953 \\
\hline & $16 \mathrm{SH} 1 \times$ & 11.03 & \\
\hline & $\mathrm{OSH} 2 \times$ & 12.07 & \\
\hline & $16 \mathrm{SH} 2 \times$ & $10 \cdot 69$ & \\
\hline
\end{tabular}

*Probability $(P)$ test of Kruskal-Wallis.

†Other is relative to the other observed behaviours, which frequency was lower than $2 \%$ of the time of observation.
Some studies have evaluated the effect of fibrous diets on the satiety of $\operatorname{dogs}{ }^{(12,17)}$. According to Burton-Freeman ${ }^{(16)}$, dietary fibre influences satiety due to its physical and chemical characteristics, such as volume, solubility and viscosity, in addition to reducing dietary energy density. Some studies indicated that soluble and fermentable fibres exert stronger effects on satiety than $\mathrm{IF}^{(2,6,18)}$. SF delay gastric emptying, making the digesta remain longer in the gastrointestinal tract ${ }^{(19)}$, in addition to possibly influencing the production of hormones related to satiety ${ }^{(1)}$. Cummings et al. ${ }^{(20)}$ found that fermentable fibres affected blood ghrelin levels in human subjects. On the other hand, Bosch et al. ${ }^{(2)}$, evaluating the supply of a dietcontaining low-fermentation fibre $(8.5 \%$ cellulose $)$ or of a diet with high-fermentation fibre (combination of inulin and beet pulp, at $8.5 \%$ inclusion level) to dogs, did not observe any difference in ghrelin concentration or in food intake.

In a previous study, carried out in our laboratory (unpublished results, Tabyta T. Sabchuk, 2013), the dietary inclusion of SH did not affect diet palatability, which suggests that food intake in the present experiment was not influenced by taste. Although food intake was not different, dogs fed the diet with 16SHhad lower ME intake than those fed the diet with $0 \mathrm{SH}$. This demonstrates that $\mathrm{SH}$ fibre reduces dietary energy, and hence could be used as a source of fibre for energy dilution in dog foods. Consistent results were obtained by Jewell $e t a l^{(21)}$, who evaluated a lowfibre control diet ( $2 \%$ crude fibre) and a high-fibre commercial diet (20\% crude fibre, but did not report the type of fibre) and also found reduced energy intake, but not food intake $(\mathrm{g} / \mathrm{d})$.

In the present study, satiety was estimated by the food intake of dogs fed once or twice daily. Despite receiving $50 \%$ in excess of their ME requirements, they did not differ in satiety, because the intake (in grams) of the diets with or without $\mathrm{SH}$ was not different. However, the dogs fed once daily presented lower intake relative to those fed twice daily, independently of the diet. This may be explained by the physical theory of intake regulation. This seems to be the most effective theory to explain food intake in dogs, because in the present experiment, dogs did not stop eating when their ME intake was supplied; only when they were no longer able to eat due to the physical limitation of the gastrointestinal tract.

This may be attributed to the feeding behaviour of dog ancestors. Wild dog packs ingest large amounts of food in a short time due to larger volume and distension capacity of their stomachs relative to domestic dogs and to the competitiveness among members of the pack ${ }^{(22)}$.

According to Bosch et al. ${ }^{(4)}$, nutrients, like fibre, influence animal behaviour, because promotes satiety, it may reduce the frequency of motivation and feeding behaviours elicited by the anxiety caused by hunger ${ }^{(3)}$. According to those authors, dogs felt less hungry when fed diets containing fermentable fibres than when fed less fermentable fibres. This is consistent with the results of the present study, in which the diet did not influence dog behaviour, possibly because $\mathrm{SH}$ were used as fibre source, which is characterised as insoluble $^{(8)}$ and with intermediate fermentability ${ }^{(23)}$.

As shown in the present study, adequate feeding management is as important to reduce/control $\mathrm{BW}$ as a energy-restricted diet. 
Moreover, the lack of influence of feeding management on dog behaviour observed in the present study may be due to the supply of food in excess of the energy requirements of dogs submitted to both practices. This may have masked the effect of satiety when dogs were fed twice daily, independently of the diet.

It is difficult to study satiety in dogs, as it is influenced by several extrinsic and intrinsic factors, as well as their interactions and to date, there is no defined protocol for its evaluation in $\operatorname{dogs}(22)$. It is possible that the behaviour of the dogs in this experiment was not affected by the presence of the researchers, as these evaluated the dogs from far (except at the time of food offer), did not interact with dogs during the behavioural evaluation, the dogs were habituated to the researchers, and the methodology was previously applied ${ }^{(24)}$. However, the use of video cameras to monitor behaviour might be better to avoid any possible influence of the presence of human subjects on dog behaviour. This might have been a limitation of the present study.

\section{Conclusions}

The inclusion of fibre, by means of $\mathrm{SH}$, in the diet does not reduce food intake $(\mathrm{g} / \mathrm{d})$ of Beagle dogs, but reduces their energy intake. Therefore, the inclusion of $16 \mathrm{SH}$ does not induce satiety in dogs fed food amounts that exceed their energy requirements. However, the physical capacity of their gastrointestinal tract limits food intake (in $\mathrm{g} / \mathrm{d}$ ) of dogs.

\section{Acknowledgements}

The authors thank Marcelo Pacheco de Carvalho and Rações VB for providing the experimental diets. There were no funding received for this work. There are no conflicts of interest to declare. T. T. S., J. R. S. and F. O. M. were responsible for the trial conduction, data analysis and manuscript writing. A. P. F., S. G. O. and A. M. guided the statistical analysis and manuscript writing.

This paper was published as part of the WALTHAM International Nutritional Sciences Symposium Proceedings 2013, publication of which was supported by an unrestricted educational grant from Mars Incorporated. The papers included in these proceedings were invited by the Guest Editor and have undergone the standard journal formal review process. They may be cited.

\section{References}

1. National Research Council (2006) Nutrient Requirements of Dogs and Cats. Washington, DC, USA: NRC, National Academy Press.

2. Bosch G, Verbrugghe A, Hesta M, et al. (2009) The effects of dietary fibre type on satiety-related hormones and voluntary food intake in dogs. Br J Nutr 102, 318-325.
3. Bosch G, Beerda B, Van De Hoek E, et al. (2009) Effect of dietary fibre type on physical activity and behaviour in kennelled dogs. Appl Anim Behav Sci 121, 32-41.

4. Bosch G, Beerda B, Hendriks WH, et al. (2007) Impact of nutrition on canine behaviour : current status and possible mechanisms. Nutr Res Rev 20, 180-194.

5. Asakawa A, Inui A, Kaga T, et al. (2001) A role of ghrelin in neuroendocrine and behavioral responses to stress in mice. Neuroendocrinology 74, 143-147.

6. Samra RA \& Anderson GH (2007) Insoluble cereal fiber reduces appetite and short-term food intake and glycemic response to food consumed 75 min later by healthy men. Am J Clin Nutr 86, 972-979.

7. Case LP, Carey DP \& Hirakawa DA (1998) Nutrição canina e felina: manual para profissionais Espanha: Harcourt Brace, 410p.

8. Cole JT, Fahey GC, Merchen NR, et al. (1999) Soybean hulls as a dietary fiber source for dogs. J Anim Sci 77, 917-924.

9. Association of the Official Analytical Chemists (1995) Official Methods of Analysis, 16 ed. Washington, DC, USA: AOAC.

10. Prosky L, Asp NG, Schweizer TF, et al. (1994) Determination of soluble dietary fiber in foods and food products: collaborative study. J AOAC 77, 690-694.

11. Association of American Feed Control Officials (2004). Dog and Cat Nutrient Profiles. Official Publications of the Association of American Feed Control Officials Incorporated. Oxford, IN, USA: AAFCO.

12. Weber M, Bissot T, Servet E, et al. (2007) A high-protein, high-fiber diet designed for weight loss improves satiety in dogs. J Vet Intern Med 21, 1203-1208.

13. Martin P, Bateson P (2007) Measuring Behaviour: An Introductory Guide. Cambridge: Cambridge University Press, p. 184.

14. Broom DM (1983) Indicators Relevant to Farm Animal Welfare. Dordrecht, Netherlands: Springer. pp. 81-87.

15. Butterwick RF \& Markwell PJ (1997) Effect of amount and type of dietary fiber on food intake in energy-restricted dogs. Am J Vet Res 58, 272-276.

16. Burton-Freeman B (2000) Symposium: dietary composition and obesity: do we need to look beyond dietary fat, dietary fiber and energy regulation. J Nutr 130, 272S-275S.

17. Palumbo GR (2009) Efeito da ingestão de amido, fibra e energia na resposta glicêmica efeito da ingestão de amido, fibra e energia na resposta glicêmica pós-prandial e saciedade em cães, 62p., Dissertação de mestrado, Universidade Estadual Paulista, Jaboticabal, São Paulo, Brasil.

18. Butterwick RF, Markwell PJ \& Thorhe CJ (1994) Dietary fiber effect of level and source of dietary fiber on food intake in the dog. J Nutr 124, 2695S-2700.

19. Yamka RM, Jamikorn U, True AD, et al. (2003) Evaluation of soyabean meal as a protein source in canine foods. Anim Feed Sci Technol 109, 121-132.

20. Cummings DE, Purnell JQ, Frayo RS, et al. (2001) A preprandial rise in plasma ghrelin levels suggests a role in meal initiation in humans. Diabetes 50, 1714-1719.

21. Jewell DE, Toll PW \& Novotny BJ (2000) Satiety reduces adiposity in dogs. Vet Therap: Res Appl Vet Med 1, 17-23.

22. Félix AP, Oliveira SG \& Maiorka A (2010) Consumo e preferência alimentar dos animais domésticos, 1st ed. Londrina, PR, Brazil: Phytobiotics.

23. Sunvold GD, Fahey GC, Merchen NR, et al. (1994) Dietary fiber fermentability of selected fibrous substrates by dog fecal microflora as influenced by diet. J Nutr 124, 2719-2720.

24. Sabchuk TT, Félix AP, Comin JG, et al. (2012) Digestibility and behavior of dogs housed in kennels or metabolic cages. Rev Bras Zootec 41, 118-122. 